\title{
Mechanochemical synthesis of $\mathrm{Ni}-\mathrm{Y} / \mathrm{CeO}_{2}$ catalyst for non- thermal plasma catalytic $\mathrm{CO}_{2}$ methanation
}

\author{
Wei Guo a, Huanhao Chen ${ }^{\text {a,* }}$ \\ ${ }^{a}$ State Key Laboratory of Materials-Oriented Chemical Engineering, College of Chemical \\ Engineering, Nanjing Tech University, Nanjing 210009, China. \\ *Corresponding author: h.chen@njtech.edu.cn (HC)
}

\section{Supporting Information (SI)}

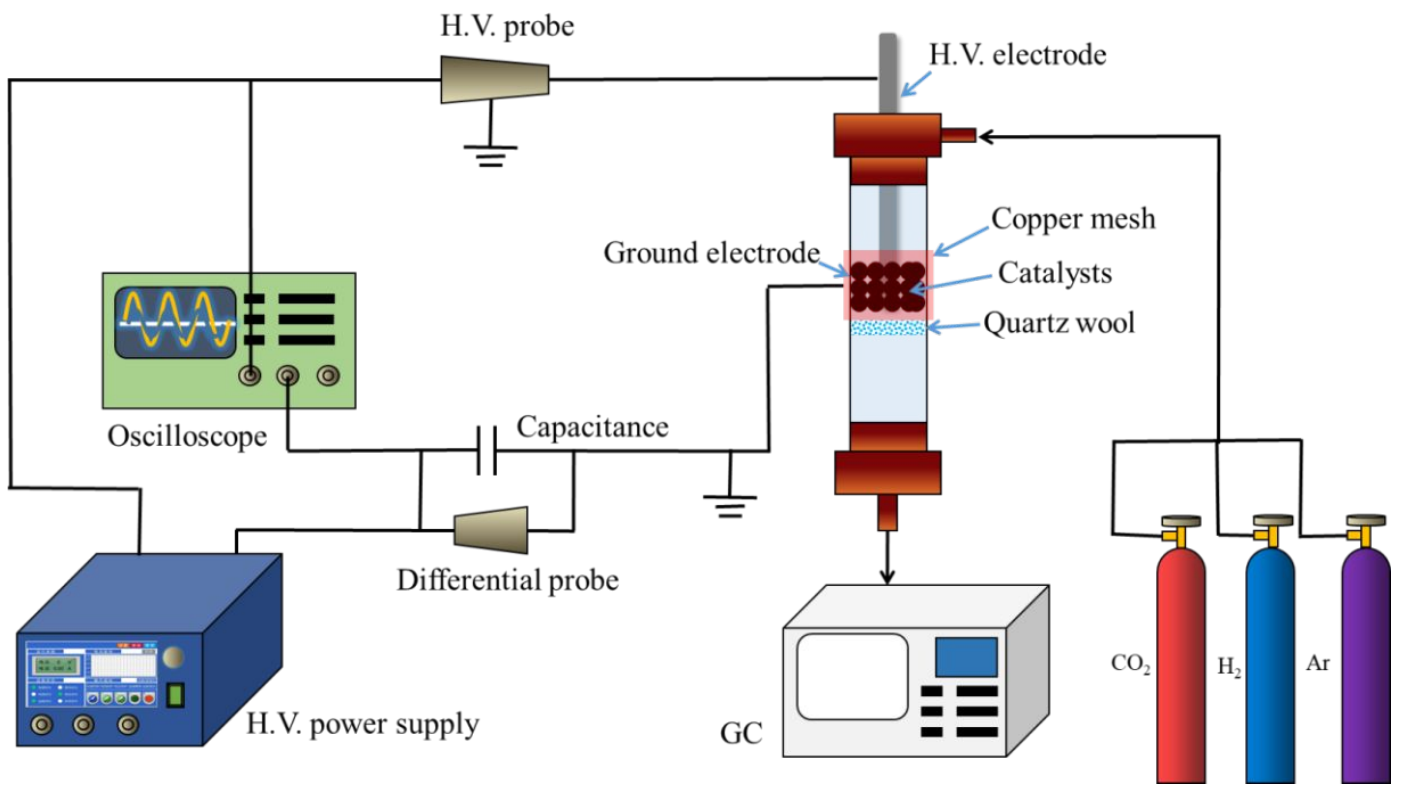

Figure S1. Schematic diagram of the NTP catalytic $\mathrm{CO}_{2}$ methanation system.

The actual metal loading in the developed catalysts in this work was determined by using inductively coupled plasma optical emission spectroscopy (ICP-OES) analysis, and the results are listed in Table S1.

Table S1. ICP-OES analysis of the as-synthesised catalysts.

\begin{tabular}{ccccc}
\hline Sample & $\begin{array}{c}\text { Nominal } \mathrm{Ni} \\
\text { contents } \\
\text { (wt.\%) }\end{array}$ & $\begin{array}{c}\text { Nominal Y } \\
\text { contents } \\
\text { (wt.\%) }\end{array}$ & $\begin{array}{c}\text { Actual Ni } \\
\text { contents } \\
\text { (wt.\%) }\end{array}$ & $\begin{array}{c}\text { Actual Y } \\
\text { contents } \\
\text { (wt.\%) }\end{array}$ \\
\hline $1 \mathrm{Ni} / \mathrm{CeO}_{2}$ & 1 & - & 1.5 & - \\
$2.5 \mathrm{Ni} / \mathrm{CeO}_{2}$ & 2.5 & - & 5.2 & - \\
$5 \mathrm{Ni} / \mathrm{CeO}_{2}$ & 5 & - & 8.5 & - \\
$7.5 \mathrm{Ni} / \mathrm{CeO}_{2}$ & 7.5 & - & 10.3 & - \\
$10 \mathrm{Ni} / \mathrm{CeO}_{2}$ & 10 & - & 18.0 & - \\
$7.5 \mathrm{Ni}-0.25 \mathrm{Y}^{-} \mathrm{CeO}_{2}$ & 7.5 & 0.25 & 8.5 & 0.4 \\
$7.5 \mathrm{Ni}-0.5 \mathrm{Y}^{-} \mathrm{CeO}_{2}$ & 7.5 & 0.5 & 9.6 & 0.7 \\
$7.5 \mathrm{Ni}-1 \mathrm{Y} / \mathrm{CeO}_{2}$ & 7.5 & 1 & 9.8 & 1.4 \\
$7.5 \mathrm{Ni}-2 \mathrm{Y} / \mathrm{CeO}_{2}$ & 7.5 & 2 & 8.7 & 3.4 \\
\hline
\end{tabular}



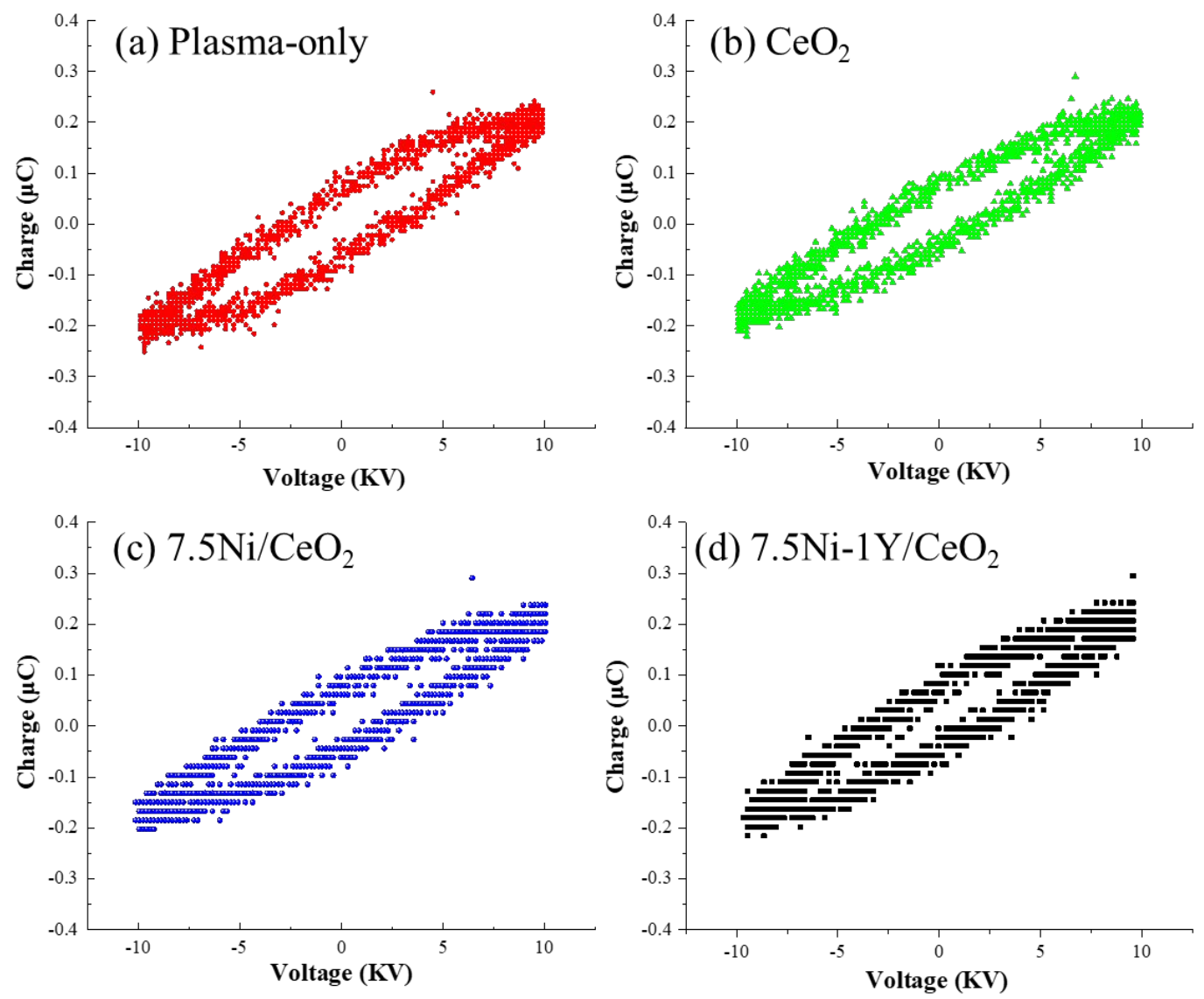

Figure S2. The Q-V Lissajous curves of (a) NTP-alone system and NTP catalytic system over the (b) $\mathrm{CeO}_{2}$, (c) $7.5 \mathrm{Ni} / \mathrm{CeO}_{2}$ and (d) $7.5 \mathrm{Ni}-1 \mathrm{Y} / \mathrm{CeO}_{2}$ catalysts packing. (Experimental conditions: feed gas = 60 vol. $\% \mathrm{H}_{2} / 15$ vol. $\% \mathrm{CO}_{2} / 25 \mathrm{vol} . \% \mathrm{Ar}$, total flow rate $=50 \mathrm{~mL}(\mathrm{STP}) \mathrm{min}^{-1}$, constant applied peak voltage and frequency of $10 \mathrm{kV}$ and $7.7 \mathrm{kHz}$ ).

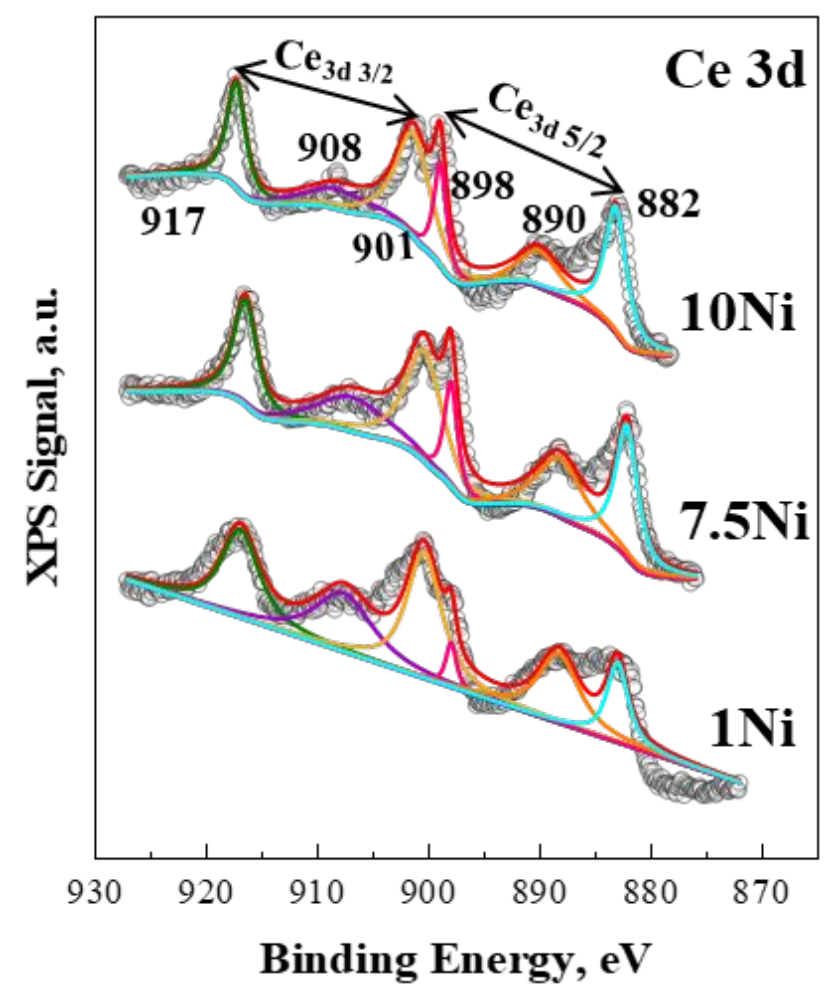

Figure S3. Ce 3d XPS spectra of the as-prepared catalysts. 


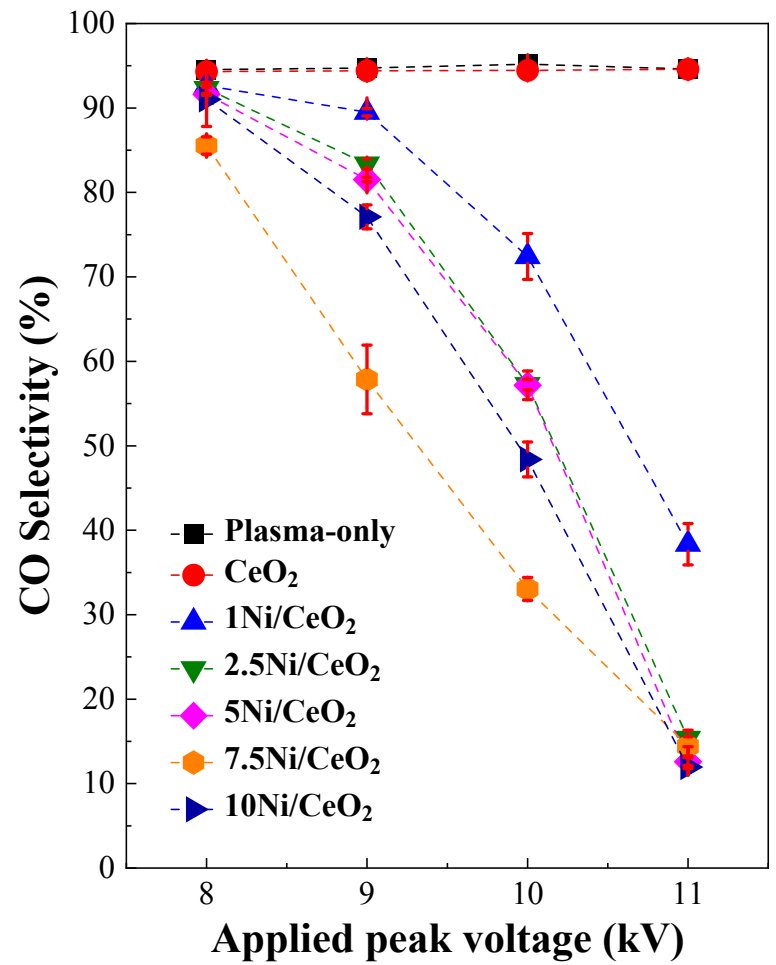

Figure S4. CO selectivity of NTP-alone system and NTP catalytic system over the $\mathrm{CeO}_{2}$, and the $\mathrm{Ni} / \mathrm{CeO}_{2}$ catalysts (with different $\mathrm{Ni}$ loadings of $1,2.5,5,7.5$, and 10 wt.\%) packing. (Experimental conditions: feed gas $=60 \mathrm{vol} . \% \mathrm{H}_{2} / 15$ vol. $\% \mathrm{CO}_{2} / 25 \mathrm{vol} . \% \mathrm{Ar}$, total flow rate $=50 \mathrm{~mL}(\mathrm{STP}) \mathrm{min}^{-1}$, varied applied peak voltage of $8-11 \mathrm{kV}$, constant frequency of $7.7 \mathrm{kHz}$ )

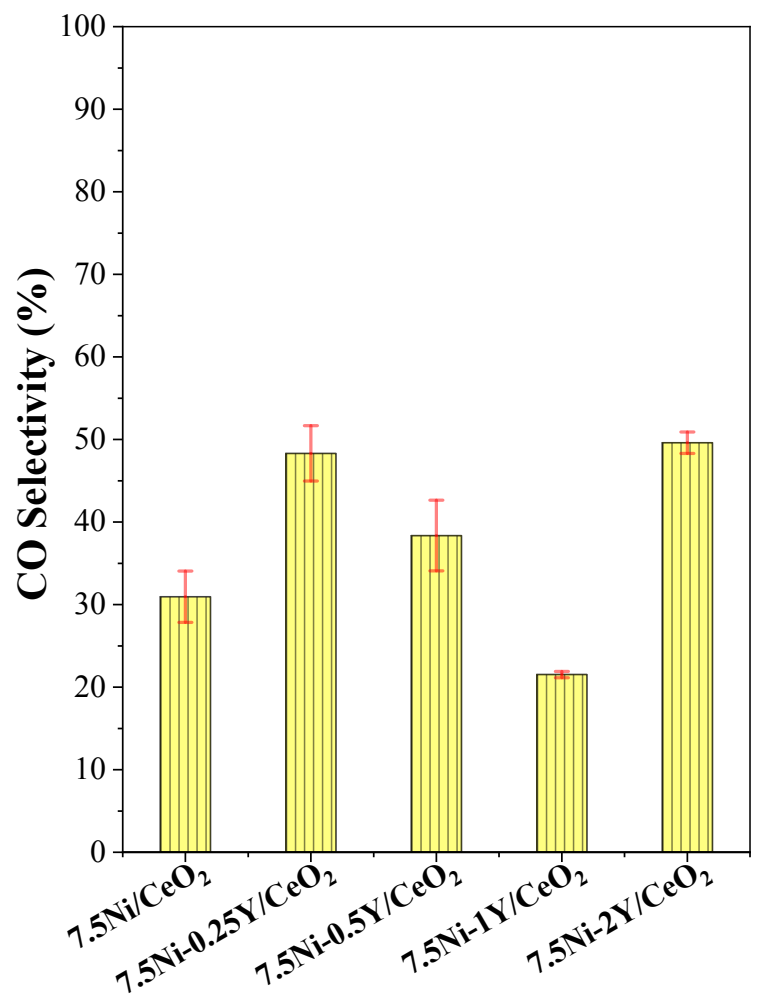

Figure S5. CO selectivity of NTP catalytic system over the $\mathrm{Ni}-\mathrm{Y} / \mathrm{CeO}_{2}$ catalysts (with constant $\mathrm{Ni}$ amount of 7.5 wt.\% and different $\mathrm{Y}$ amounts of 0, 0.25, 0.5, 1, and 2 wt.\%) packing. (Experimental conditions: feed gas $=60$ vol. $\% \mathrm{H}_{2} / 15$ vol. $\% \mathrm{CO}_{2} / 25$ vol. $\% \mathrm{Ar}$, total flow rate $=50 \mathrm{~mL}(\mathrm{STP}) \mathrm{min}^{-1}$, constant applied peak voltage and frequency of $10 \mathrm{kV}$ and $7.7 \mathrm{kHz}$ ) 


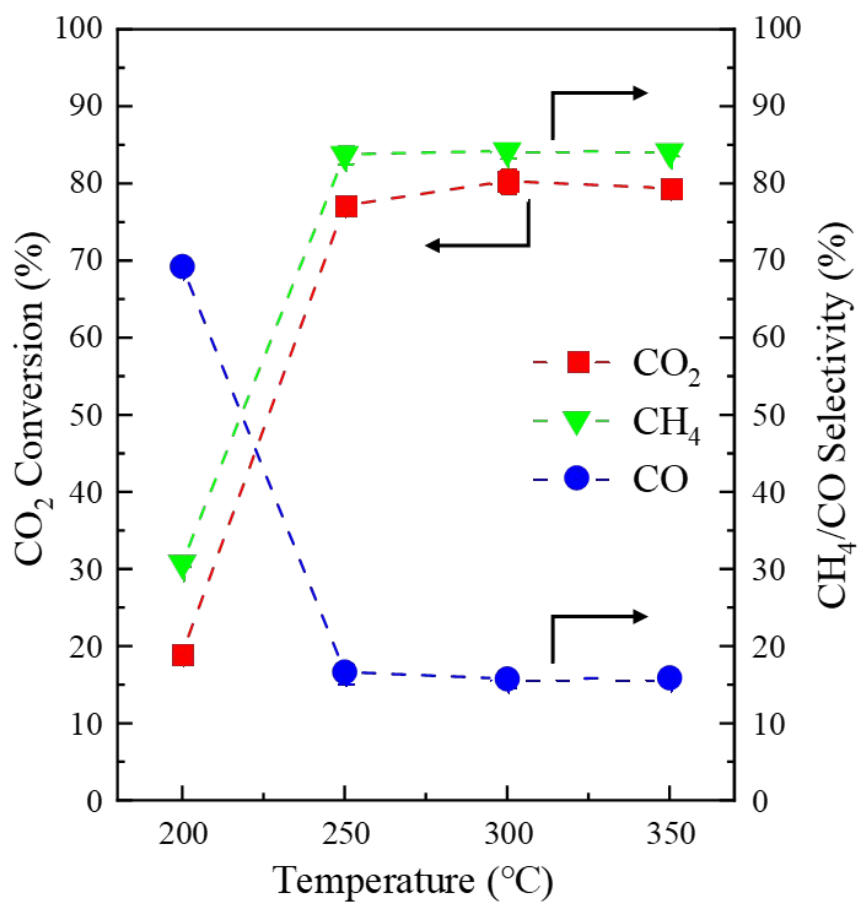

Figure S6. $\mathrm{CO}_{2}$ methanation performance of thermally catalytic system over the $7.5 \mathrm{Ni}-1 \mathrm{Y} / \mathrm{CeO}_{2}$ catalyst. (Experimental conditions: feed gas $=60 \mathrm{vol} . \% \mathrm{H}_{2} / 15 \mathrm{vol} . \% \mathrm{CO}_{2} / 25 \mathrm{vol} . \% \mathrm{Ar}$, total flow rate $=$ $50 \mathrm{~mL} \mathrm{~min}{ }^{-1}$, constant reactor pressure of 1 bar, reactor temperature of $200-350{ }^{\circ} \mathrm{C}$ )

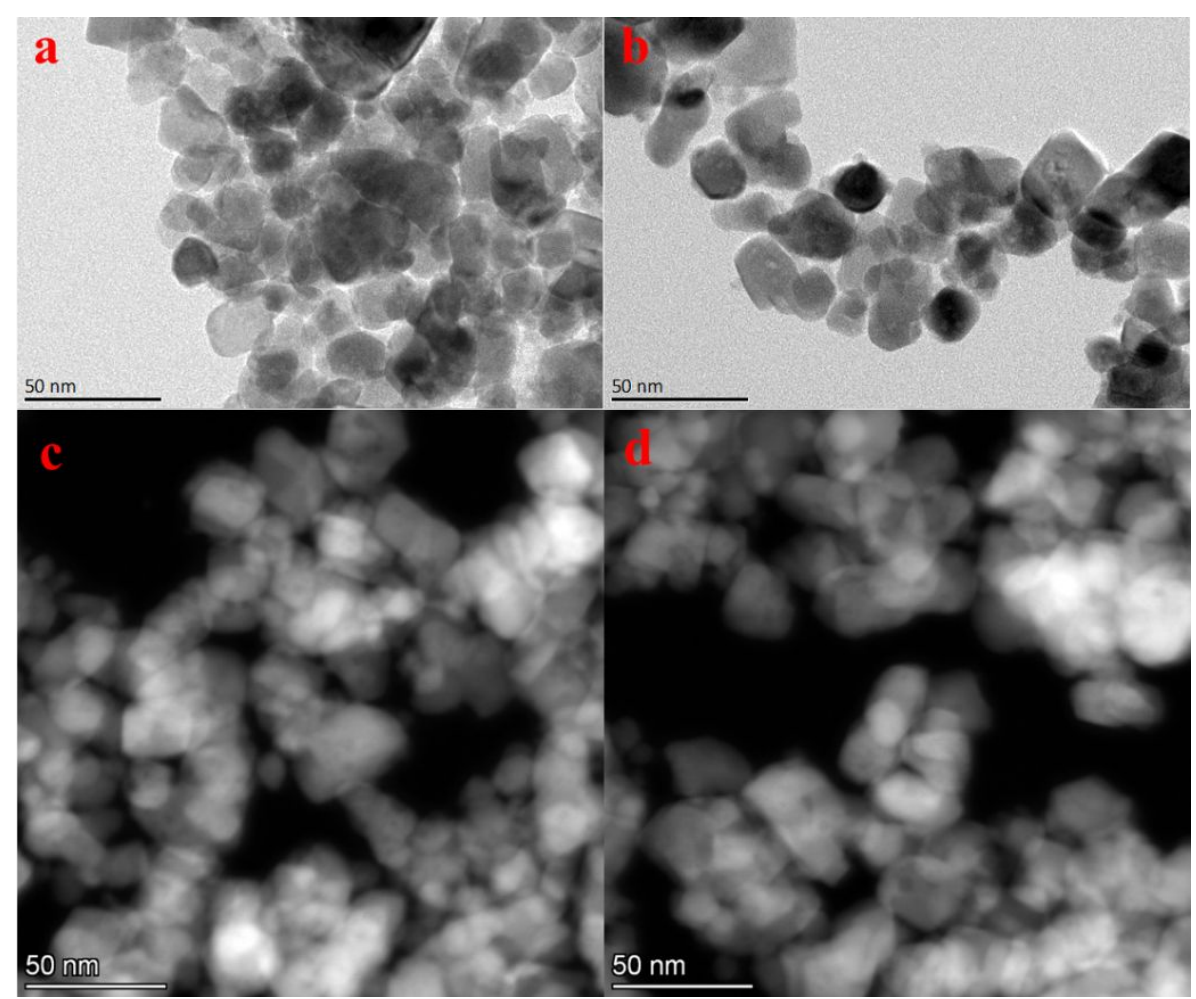

Figure S7. TEM and HAADF-STEM images of the reduced catalysts: (a and c) $7.5 \mathrm{Ni} / \mathrm{CeO}_{2},(\mathrm{~b}$ and d) 7.5 $\mathrm{Ni}-1 \mathrm{Y} / \mathrm{CeO}_{2}$. 

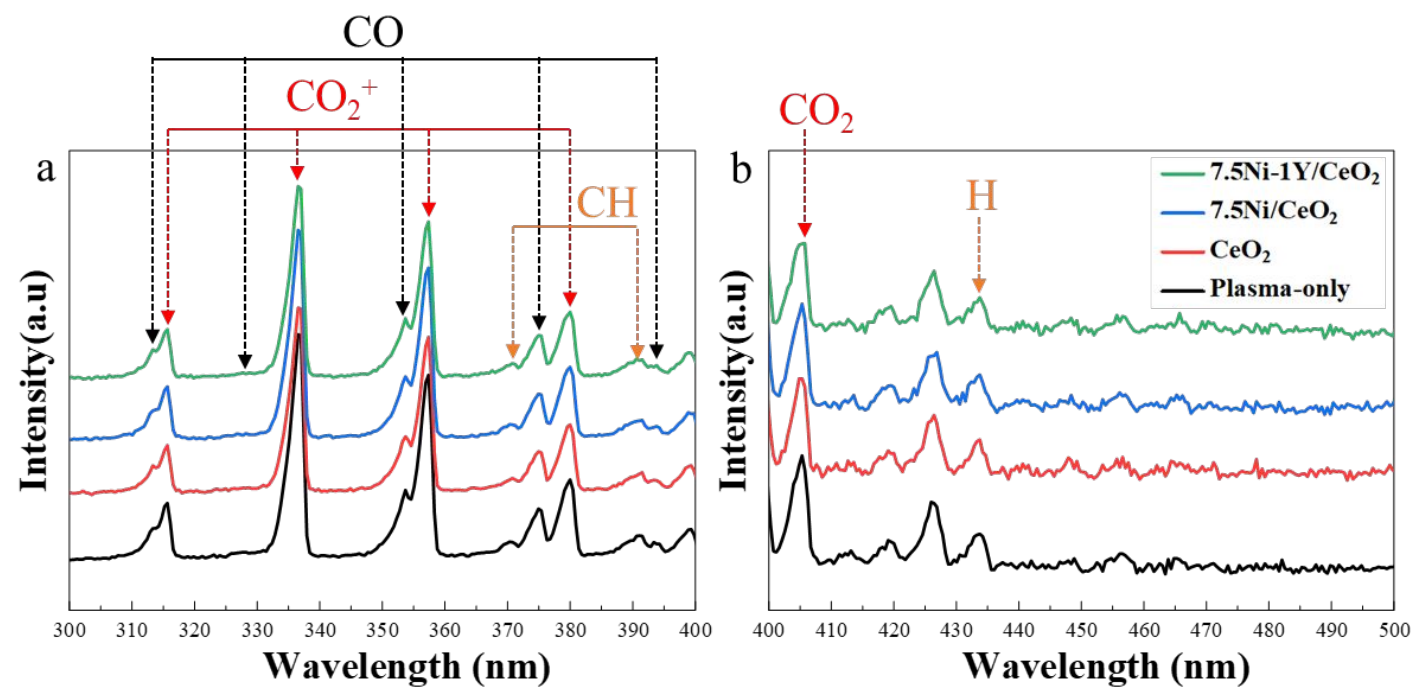

Figure S8. Comparative OES spectra of $\mathrm{CO}^{2+}, \mathrm{CO}, \mathrm{CH}, \mathrm{CO}_{2}, \mathrm{H}$ for NTP-alone system and NTP catalytic system over the $\mathrm{CeO}_{2}, 7.5 \mathrm{Ni} / \mathrm{CeO}_{2}$ and $7.5 \mathrm{Ni}-1 \mathrm{Y} / \mathrm{CeO}_{2}$ catalysts packing with different wavelength range: (a) 300-400 nm, and (b) $400-500 \mathrm{~nm}$. (Experimental conditions: feed gas $=60$ vol. $\% \mathrm{H}_{2} / 15$ vol. $\% \mathrm{CO}_{2} / 25$ vol. $\% \mathrm{Ar}$, total flow rate $=50 \mathrm{~mL}(\mathrm{STP}) \mathrm{min}^{-1}$, constant applied peak voltage and frequency of $10 \mathrm{kV}$ and $7.7 \mathrm{kHz}$ ) 